\title{
Problemas Ginecológicos mais Freqüentes em Mulheres Soropositivas para 0 HIV
}

\author{
The Most Frequent Gynecological Problems in HIV-infected Women
}

\begin{abstract}
Victor Hugo de Melo ${ }^{1}$, Angela Cristina Labanca de Araújo ${ }^{2}$, Suzana Maria Pires do Rio ${ }^{3}$ Lúcia Porto Fonseca de Castro $^{1}$, Andrea Alves de Azevedo ${ }^{1}$, Mariana Moreira de Castro ${ }^{1}$
\end{abstract}

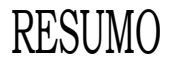

\begin{abstract}
Objetivo: apresentar os achados ginecológicos mais freqüentes de uma coorte de 300 mulheres infectadas pelo HIV, acompanhadas ambulatorialmente.

Métodos: estudo prospectivo e descritivo de mulheres HIV-soropositivas atendidas em clinica ginecológica, no periodo de novembro de 1996 a dezembro de 2002. As pacientes foram submetidas ao protocolo de atendimento ginecológico que incluiu anamnese, exame ginecológico, colpocitologia oncótica (Papanicolaou), pesquisa de HPV (PCR) e colposcopia. A biópsia cervical, quando necessária, foi realizada. Os dados foram armazenados e analisados no Epi-Info, versão 6.0.

Resultados: a idade média foi 34,5 anos. Destaca-se o pequeno número de parceiros sexuais, média de três parceiros, e a predominância do contágio heterossexual: 271 (90,6\%) pacientes adquiriram o virus por meio do contato sexual com seus parceiros. Foi alta a prevalencia de neoplasias intra-epiteliais cervicais (NIC), representando 21,7\% do total da amostra. Dentre as 109 pacientes submetidas a PCR encontraram-se 89 (81,7\%) com algum genótipo do HPV. Esfregaço inflamatório à citologia esteve presente em $69 \%$ das pacientes.

Conclusões: a infecção pelo HIV se associa com freqüência a NIC e a processos infecciosos genitais, em especial o HPV.
\end{abstract}

PALAVRAS-CHAVE: AIDS. Papilomavirus humano. Citologia cérvico-vaginal. Colo do útero: lesões pré-neoplásicas. Reação em cadeia por polimerase.

\section{Introdução}

Aproximadamente 42 milhões de pessoas no mundo apresentavam-se infectadas pelo virus da imunodeficiência humana (HIV) no final de 2002, sendo que 19,2 milhões eram mulheres. Ocorreram cinco milhões de novas infecções somente

${ }^{1}$ Faculdade de Medicina da UFMG

${ }^{2}$ Centro de Treinamento e Referência em Doenças Infecciosas e Parasitárias Orestes Diniz (CTR-DIP) da Prefeitura Municipal de Belo Horizonte e Hospital das Clínicas da UFMG

${ }^{3}$ Faculdade de Medicina da Universidade Presidente Antônio Carlos - UNIPAC

Correspondência:

Victor Hugo de Melo

Rua dos Otoni 909, sala 1910 - Edificio MedCenter

30250-170 - Belo Horizonte - MG

Fones: (31) 3273-5273 / 3273-3233

Fax: (31) 3273-0800

e-mail: victormelo@terra.com.br no ano de 2002, o que significa 14.000 a cada dia. Dois milhões de mulheres foram infectadas nesse ano; destas novas infecções, 3,5 milhões ocorreram na África Subsaariana ${ }^{1}$.

As estatísticas mundiais indicam pela primeira vez números iguais para homens e mulheres. Elas também já representam metade dos casos infectados entre indivíduos jovens entre $15 \mathrm{e}$ 24 anos. Em 2002, 800 mil crianças foram infectadas pelo virus, apesar das tentativas de profilaxia da transmissão materno-fetal com o uso de drogas anti-retrovirais. Nesse mesmo ano 3,1 milhões de pessoas morreram de AIDS, incluindo 610 mil crianças ${ }^{1,2}$.

Dentre as pessoas atualmente infectadas, $85 \%$ estão em idade reprodutiva. As mulheres adquirem a infecção principalmente por meio do contágio heterossexual. Entre menores de 12 anos a transmissão materno-fetal é responsável por $90 \%$ dos casos notificados ${ }^{1,2}$. 
No Brasil, existem aproximadamente 600 mil pessoas infectadas pelo HIV. Entre 1980 e 2001 houve 222.356 casos notificados de AIDS, dos quais $50 \%$ faleceram. Até o primeiro semestre de 2002 havia cerca de 238 mil casos de AIDS, dos quais 65 mil eram mulheres $(30,6 \%)^{3}$. Desde 1996, com a distribuição gratuita da associação de medicamentos anti-retrovirais pelo governo brasileiro, a evolução dos pacientes para o estágio de AIDS vem sendo reduzida. Registraram-se 20 mil novos casos em 1999 e, em 2000, houve declínio para 15 mil novos casos ${ }^{4}$.

O principal motivo para uma mulher infectada procurar assistência médica parece ser o desenvolvimento de infecção ginecológica. Candidiase recorrente, infecção genital crônica pelo vírus do herpes simples, doença inflamatória pélvica, com incidência elevada de abscesso tuboovariano, e sífilis podem ser manifestações iniciais de mulheres HIV-soropositivas, que justificam a pesquisa do virus naquelas com status sorológico desconhecido ${ }^{5-8}$. A infecção pelo papilomavírus humano (HPV) é significativamente mais comum entre mulheres soropositivas $(73,2 \%)$ do que nas soronegativas $(23,7 \%)^{9}$. Por sua vez, paciente soropositiva, com HPV, apresenta risco 13 vezes maior do que as soronegativas de desenvolver neoplasia intra-epitelial cervical (NIC) ${ }^{10}$.

Anormalidades na colpocitologia oncótica são mais freqüentes entre as mulheres HIV-soropositivas, quando comparadas às soronegativas ${ }^{2,11-14}$. O HIV é fator de risco para o câncer cervical uterino $^{12}$. A prevalência de lesões intrepiteliais escamosas em pacientes HIV-soropositivas é significativamente mais elevada do que na população feminina em geral ${ }^{15-20}$. Aproximadamente metade das lesões é de alto grau ${ }^{12}$.

O objetivo desse estudo é apresentar os problemas mais freqüentemente encontrados no acompanhamento ginecológico de mulheres soropositivas para o HIV, para evidenciar os aspectos mais relevantes apresentados por elas no momento da primeira consulta.

\section{Pacientes e Métodos}

Realizou-se estudo prospectivo (coorte aberta) e descritivo de 300 mulheres HIV-soropositivas atendidas na clínica ginecológica do Centro de Treinamento e Referência em Doenças Infecciosas e Parasitárias Orestes Diniz (CTR-DIP), convênio entre a Prefeitura Municipal de Belo Horizonte, a Faculdade de Medicina e o Hospital das Clínicas da UFMG, no período de novembro de
1996 a dezembro de 2002. Os diagnósticos foram feitos com teste ELISA (ensaio imunoenzimático) e teste sorológico confirmatório (Western blot ou imunofluorescência indireta) da presença do HIV previamente. $\mathrm{O}$ atendimento ginecológico incluiu anamnese, exame ginecológico, colpocitologia oncótica, coleta de material para pesquisa de HPV e biópsia cervical, quando indicada pela colposcopia. O seguimento ginecológico destas pacientes vem sendo realizado semestralmente. Não foram incluídas gestantes porque elas são acompanhadas em outro local.

As caracteristicas pessoais e comportamentais das pacientes na primeira consulta ginecológica são mostradas na Tabela 1 . A média de idade foi 34,5 anos e grande parte das pacientes era solteira ou separada. Viuvez foi achado prevalente. Percebeu-se que 60,8\% das mulheres tiveram até três parceiros sexuais durante toda a sua vida, e a forma de contágio predominante foi a sexual. Evidenciou-se perfil de baixa escolaridade. Dentre 266 mulheres que puderam ser classificadas na primeira consulta, 117 (44\%) já se encontravam no estágio de AIDS.

O exame ginecológico foi realizado segundo o protocolo estabelecido: inspeção, introdução do espéculo vaginal, coleta de material para colpocitologia oncótica cervical e pesquisa de HPV, pela técnica de PCR (polymerase chain reaction).

Após a colocação do espéculo vaginal era realizada coleta de material da ectocérvice (junção escamo-colunar), com o auxílio de espátula de Ayre. Esta, a seguir, era quebrada e colocada em tubo de ensaio de $12 \mathrm{~cm}$ de comprimento, contendo $3 \mathrm{~mL}$ de soro fisiológico. O tubo era rotulado e encaminhado ao Núcleo de Pesquisa e Apoio Diagnóstico (NUPAD) da Faculdade de Medicina da UFMG, para realização da PCR.

O passo seguinte era a coleta de material para a citologia oncótica, utilizando-se a espátula de Ayre para o raspado da ectocérvice e a escova (cytobrush) para a coleta do material da endocérvice. O material citológico foi enviado ao Departamento de Anatomia Patológica da Faculdade de Medicina da UFMG. Os laudos foram emitidos segundo a classificação de Papanicolaou e Traut (1943).

A seguir, após limpeza do colo uterino com ácido acético a $3 \%$, era realizada a colposcopia, com o objetivo de pesquisar áreas aceto-brancas. Após essa primeira avaliação colposcópica o colo era corado com solução de Schiller e novamente observado ao colposcópio. Toda área iodo-negativa foi estudada, assim como a presença de pontilhados, mosaicos e outras lesões colposcópicas. O desenho da lesão foi registrado no prontuário de cada 
paciente. O passo seguinte era a aplicação de solução de bissulfito de sódio a 5\% para "descolorir" o colo. Aplicava-se novamente o ácido acético a $3 \%$ para novo estudo colposcópico, com o objetivo de relacionar as áreas aceto-brancas e as iodonegativas e selecionar a área mais alterada para realizar a biópsia. Para classificação das lesões cervicais foi adotada a nomenclatura proposta pelo Comitê da Federação Internacional de Patologia Cervical e Colposcopia ${ }^{21}$. Foi utilizado o colposcópio da marca Liesegang, modelo padrão.

Tabela 1 - Características pessoais e comportamentais das pacientes HIV-soropositivas atendidas no ambulatório de ginecologia do CTR-DIP.

\begin{tabular}{|c|c|c|}
\hline Características & $\mathrm{n}^{\#}$ & $\%$ \\
\hline Idade & 300 & 100 \\
\hline \multicolumn{3}{|l|}{ Média (34,5 anos) } \\
\hline \multicolumn{3}{|l|}{ Mediana (33 anos) } \\
\hline $\begin{array}{l}\text { Estado civil } \\
\text { Solteira/Separada }\end{array}$ & 296 & 183 \\
\hline Viúva & 50 & 16,9 \\
\hline União estável & 103 & 34,8 \\
\hline Escolaridade & 299 & \\
\hline Nenhuma & 13 & 4.3 \\
\hline $1^{\circ} \mathrm{Grau}$ incompleto & 152 & 50,8 \\
\hline $1^{0}$ Grau completo & 83 & 27,8 \\
\hline $2^{\circ}$ Grau completo & 45 & 15,1 \\
\hline $3^{\circ} \mathrm{Grau}$ completo & 6 & 2,0 \\
\hline Forma de contágio & 299 & 90,6 \\
\hline Sexual & 271 & 3,0 \\
\hline Sangue $(U D I)^{*}$ & 9 & \\
\hline Não sabe & 19 & 6,4 \\
\hline Número de parceiros & 296 & \\
\hline Um & 63 & 21,3 \\
\hline Dois & 59 & 19,9 \\
\hline Três & 58 & 19,6 \\
\hline Quatro ou mais & 116 & 39,2 \\
\hline Atividade sexual atual & 300 & \\
\hline Sim & 167 & 55,7 \\
\hline Não & 133 & 44,3 \\
\hline Classificação do CDC (1993) ** & 266 & \\
\hline AIDS & 117 & 44,0 \\
\hline Não-AIDS & 133 & 560 \\
\hline
\end{tabular}

*UDI - Usuária de droga injetável.

${ }^{* *} A$ classificação do $\mathrm{CDC}^{23}$ é adotada internacionalmente.

"Casos com informações para cada item.

Toda lesão foi biopsiada sob visão colposcópica, utilizando-se pinça de Gaylor-Medina. O material biopsiado foi fixado em formol a $10 \%$ e processado para estudo histológico de rotina, com inclusão em parafina. Foram realizados cortes com $5 \mu \mathrm{m}$ de espessura dos blocos de parafina, que eram corados pela hematoxilina-eosina e examinados no
Serviço de Biópsias do Departamento de Anatomia Patológica da Faculdade de Medicina da UFMG, sempre pelo mesmo patologista. Os laudos foram emitidos segundo a Classificação de Richart ${ }^{22}$.

Para a classificação das pacientes em relação ao seu status sorológico utilizaram-se as categorias propostas pelo CDC (Centers for Diseases Control and Prevention) em $1993^{23}$.

Todas as pacientes assinaram, na primeira consulta, termo de consentimento livre e esclarecido, em que se explicou que as informações coletadas poderiam ser utilizadas para publicações científicas. Este estudo foi aprovado pelo Comitê de Ética em Pesquisa da UFMG.

Os dados foram armazenados e analisados no software Epi-Info, versão 6.0.

\section{Resultados}

A análise dos dados obtidos nas primeiras consultas de 300 mulheres portadoras do HIV, atendidas na clínica ginecológica do CTR-DIP, nos possibilitou chegar aos resultados que apresentamos a seguir.

Os antecedentes ginecológicos estão apresentados na Tabela 2. A média de idade da menarca foi 13,3 anos. Percebe-se que a grande maioria $(\mathrm{n}=205 ; 73,5 \%)$ manteve ciclos menstruais regulares. A ocorrência de algum tipo de doença sexualmente transmissivel (DST) foi relatada por 100 mulheres $(33,4 \%)$ e $91,8 \%$ delas já havia se submetido a algum tratamento ginecológico anterior. A maioria usava algum método contraceptivo $(\mathrm{n}=206 ; 69,4 \%)$ à época da primeira consulta $\mathrm{e}$ somente $41 \%$ relatava que seus parceiros anteriores usavam previamente o condom.

Os achados do exame ginecológico são mostrados na Tabela 3. Percebe-se que quase metade da coorte $(n=139 ; 47,4 \%)$ evidenciou teste de Schiller positivo. A colposcopia mostrou alterações da cérvice em $159(61,4 \%)$ dentre as 259 pacientes em que foi realizada. As alterações mais freqüentes foram epitélio aceto-branco $(25,1 \%)$ e o pontilhado $(20 \%)$.

Nos achados citológicos somente $27(9,0 \%)$ pacientes apresentaram exames sem alterações. Do restante, 83,6\% apresentaram alguma alteração, excluídos os exames insatisfatórios e outros achados. As NIC detectadas pela citologia representaram $14,6 \%$ dos casos, ao passo que $12 \%$ foram encontradas alterações citoarquiteturais compatíveis com a infecção pelo HPV. Os achados citológicos mais freqüentes foram: inflamação $(69,0 \%)$, metaplasia escamosa (58\%) e infecções específicas por cândida, gardnerela e tricomonas $(29,6 \%)$. 
Tabela 2 - Antecedentes ginecológicos das mulheres HIV-soropositivas atendidas no ambulatório de ginecologia do CTR-DIP.

\begin{tabular}{|c|c|c|}
\hline Antecedentes & $\mathrm{n}^{\#}$ & $\%$ \\
\hline Menarca & 300 & 10 \\
\hline \multicolumn{3}{|l|}{ Média (13,3 anos) } \\
\hline \multicolumn{3}{|l|}{ Mediana (13 anos) } \\
\hline Ciclos menstruais & 279 & \\
\hline Regulares & 205 & 73,50 \\
\hline Irregulares & 74 & 26,50 \\
\hline DST & 299 & \\
\hline Sim & 100 & 33 \\
\hline Não & 192 & 64 \\
\hline Não sabe & 7 & \\
\hline Tratamentos anteriores & 294 & \\
\hline Corrimento & 175 & 59 \\
\hline DIP* & 21 & \\
\hline Cauterização & 74 & 25 \\
\hline Nenhum & 24 & \\
\hline Contracepção atual & 297 & \\
\hline Sim & 206 & 69 \\
\hline Não & 91 & 30 \\
\hline Uso regular de condom & 231 & \\
\hline Atualmente & 108 & \\
\hline Anteriormente & 123 & 41 \\
\hline
\end{tabular}

*DIP - Doença inflamatória pélvica

\#Casos com informações para cada item.

Das 122 biópsias realizadas, somente duas apresentaram colo normal. Como achado isolado foi observado cervicite em 54 pacientes $(44,3 \%)$. A NIC foi detectada em 65 pacientes, representando $53,3 \%$ das pacientes biopsiadas e $21,7 \%$ do total de mulheres do estudo. O carcinoma microinvasor foi diagnosticado em uma paciente. As NIC assim se distribuíram: NIC 1 em 42 (60,4\%) mulheres, NIC 2 em $16(20,4 \%)$ e NIC 3 em sete $(19,1 \%)$. Foram detectados $65(54,1 \%)$ casos de HPV à biópsia. Nas pacientes nas quais foi detectado o HPV pelo método de PCR encontrou-se maior freqüência dos tipos $16(48,3 \%)$ e $6(44,9 \%)$.

\section{Discussão}

A proposição deste estudo foi apresentar os problemas ginecológicos mais comuns detectados em coorte de 300 mulheres HIV-soropositivas atendidas no CTR-DIP.

A transmissão sexual do vírus ocorreu em $90,6 \%$ das mulheres. Somente $3 \%$ ocorreu em usuárias de drogas injetáveis e $6,4 \%$ não souberam identificar a causa da infecção. Heard et al. ${ }^{13}$
Tabela 3 - Características do exame ginecológico das pacientes HIV-soropositivas atendidas no ambulatório de ginecologia do CTR-DIP.

\begin{tabular}{lcr}
\hline $\begin{array}{l}\text { Características do } \\
\text { colo do útero }\end{array}$ & $\mathbf{n}^{\#}$ & \\
\hline Teste de Schiller & & \\
$\quad$ Positivo & 293 & 47,4 \\
$\quad$ Negativo & 139 & 52,6 \\
Colposcopia & 154 & \\
$\quad$ Normal & 259 & 38,6 \\
Alterada & 100 & 61,4 \\
Citologia & 159 & \\
Sem alterações & 300 & 9,0 \\
Alterações inflamatórias & 27 & 69,0 \\
Lesões intra-epiteliais de baixo & 207 & \\
e alto grau & & 14,6 \\
Insatisfatória e outras & 44 & 7,4 \\
Biópsia & 22 & 1,6 \\
Normal & 122 & 98,4 \\
Alterada & 2 & 53,3 \\
NIC* & 120 & 0,8 \\
Carcinoma micro-invasor & 65 & 44,3 \\
Cervicite & 1 & \\
PCR para HPV & 54 & \\
Detectado & 109 & \\
Não detectado & 89 & \\
\hline
\end{tabular}

*NIC - Neoplasia intraepitelial cervical.

"Casos com informações para cada item.

encontraram proporções diferentes de transmissão em seu estudo envolvendo 307 pacientes HIVsoropositivas: $60 \%$ por contato heterossexual; $29 \%$ pelo uso de drogas endovenosas, $5 \%$ por transfusão de sangue ou seus derivados e $6 \%$ por causa desconhecida.

A infecção pelo HIV não traz transtornos ao ciclo menstrual da mulher. Nossa casuística confirma essa assertiva: mais de $70 \%$ das pacientes apresentava ciclos menstruais regulares. Aqui também estão incluídas as usuárias de anticoncepcionais orais ou injetáveis, que representam pequena parcela da amostra $(5 \%)$.

A freqüência de DST é elevada entre pacientes HIV-soropositivas. Descreve-se a co-infecção entre HIV e sifilis e sabe-se que a presença de outras DST aumenta o risco tanto para o contágio quanto para a transmissão do HIV ${ }^{2,5,7,8}$. As DST facilitam a transmissão do HIV devido às úlceras e inflamações nas mucosas da vulva, vagina e colo uterino. Já se demonstrou redução de $42 \%$ dos casos incidentes após agressivo programa de tratamento de DST ${ }^{14}$.

Dentre os tratamentos ginecológicos anteriores destacam-se as cauterizações cervicais. Sabe-se que cauterização elétrica e a conização 
cervical são os procedimentos mais comumente realizados em mulheres HIV-positivas. Esses tratamentos mais invasivos são justificados pela alta recorrência de NIC após um ano (40 a 60\% nas HIV positivas e $10 \%$ nas soronegativas) ${ }^{2}$.

Não foram encontradas alterações significativas nas regiões vulvar e perianal destas mulheres. Exceção se faz a algumas mulheres que apresentaram condiloma acuminado nestas regiões. Já se demonstrou que o câncer anal é mais comum entre homossexuais masculinos ${ }^{11}$, mas este câncer tem sido diagnosticado com mais freqüência também em mulheres soropositivas para o HIV, recomendando-se o exame rotineiro da região perianal e biópsia de áreas suspeitas ${ }^{20}$. Além disto, o risco de carcinoma in situ e invasivo na vulva e vagina pode ser até cinco vezes maior nessas mulheres do que na população feminina como um todo ${ }^{20}$.

O teste de Schiller utilizando solução de Lugol forte foi positivo em $139(47,4 \%)$ pacientes. Isso se deve ao aumento da incidência de HPV e NIC nessas pacientes ${ }^{2,20}$.

O estudo citológico apresentou grande freqüência de esfregaços com alterações inflamatórias, NIC e HPV. No entanto, detectou menos pacientes com NIC do que as diagnosticadas pela biópsia dirigida, respectivamente 14 e 21,7\%. Este achado está de acordo com Auge et al. ${ }^{18}$, que demonstraram menor sensibilidade da colpocitologia oncótica no rastreamento das NIC entre as mulheres HIV-soropositivas. Encontraram 52,5\% de resultados falso-negativos para NIC no exame citopatológico da sua amostra. É importante lembrar que o exame citológico é indicado para rastreamento de neoplasias, não sendo instrumento diagnóstico acurado.

Tendo em vista a falha da avaliação citológica cervical para detectar as NIC, esses mesmos autores, baseados em protocolo do American College of Obstetricians and Gynecologists (ACOG), propõem a associação do exame colposcópico ao colpocitológico para rastrear as lesões cervicais das mulheres HIVsoropositivas a cada seis meses, desde que apresentem contagem de células CD4 acima de 200 células $/ \mathrm{mm}^{3}$. Para as que apresentam contagem com números inferiores propõem-se exame citológico trimestral e colposcopia semestral. Temos utilizado o rastreamento com colposcopia e colpocitologia semestralmente, independentemente da contagem de células CD4. A recomendação mais recente do CDC é realizar citologia oncótica anualmente, após dois exames normais ${ }^{20}$.

As alterações inflamatórias mais freqüentes entre as mulheres do presente estudo foram decorrentes de infecções como vaginose bacteriana, tricomoníase e candidíase, que são também achados comuns em mulheres soronegativas. No entanto, a candidiase vulvovaginal persistente, pouco responsiva a tratamento, decorre da depressão da imunidade, sendo considerada categoria B pelo $\mathrm{CDC}$, quando presente em mulheres HIV-soropositivas $^{2}$. Vaginose bacteriana, tricomoniase e herpes genital são importantes co-fatores para a transmissão do $\mathrm{HIV}^{8}$. Estudo de coorte mostrou que a vaginose bacteriana é mais prevalente e persistente entre as mulheres infectadas pelo $\mathrm{HIV}^{6}$. A imunossupressão associada ao vírus parece ser importante fator de risco para as situações na quais existem quadros mais graves de vaginoses ${ }^{5,6}$.

Na classificação do CDC de 1993 designouse NIC de alto grau ("displasia cervical moderada e acentuada") como categoria B e câncer cervical invasivo como $\mathrm{C}^{15,23}$. Por sua vez, nas pacientes HIV-soropositivas, a NIC é mais freqüente e recorrente, de progressão mais rápida, e apresenta pior resposta ao tratamento padrão ${ }^{2,10,12,16,20}$. Essa maior agressividade tem relação direta com os genótipos de alto risco do HPV, mais freqüentes na cérvix das mulheres HIV-soropositivas ${ }^{15,16,19}$. O uso de HAART (high active antiretroviral therapy) forma de terapia medicamentosa agressiva em que se utilizam três ou mais anti-retrovirais - parece ser promissor na cura da NIC, pelo incremento da imunidade celular ${ }^{2,12,20}$.

O HPV também foi mais freqüente na nossa amostra, presente em $81,7 \%$ das pacientes que tiveram materiais examinados por PCR. Na literatura consultada a prevalência nas mulheres soropositivas variou de 52,8 a $73,2 \%$ entre as HIVsoropositivas e de 23,7 a $26 \%$ dentre as soronegativas $2,9,13,15,17,19$. Encontramos, na grande maioria das mulheres, a infecção por múltiplos genótipos do HPV, sendo que os mais freqüentes foram os tipos de alto risco 16, 18 e 31, e o tipo 6, de baixo risco. Tanto a multiplicidade de genótipos quanto os tipos de HPV encontrados estão em concordância com a literatura ${ }^{13,15,17,19}$.

A prevalência de biópsias confirmando NIC em mulheres HIV-soropositivas é elevada, podendo chegar a $42 \%^{12}$. Em nossa coorte as NIC representaram 21,7\% da amostra. Estudo nacional, com 99 pacientes HIV-soropositivas e 104 soronegativas, encontrou 15,2 e 3,8\% de NIC, respectivamente ${ }^{18}$.

Encontramos um caso de microcarcinoma invasor e nenhum de câncer invasivo. Apesar de se ter demonstrado que as mulheres HIV-soropositivas têm risco duas vezes maior de apresentarem câncer cervical invasivo o que justificou sua inclusão como doença indicadora de AIDS pelo $\mathrm{CDC}^{23}$, em 1993, quando comparadas às soronegativas, estudos mais recentes não têm encontrado este câncer com maior freqüência, mesmo na África, onde é muito alta a prevalência do HIV ${ }^{20}$.

Concluímos que a infecção pelo HIV se associa com freqüência a NIC e a processos infecciosos genitais, em especial o HPV. 


\section{ABSTRACT}

Purpose: to present the most frequent gynecologic results in a cohort of 300 outpatient HIV-infected women.

Methods: this is a prospective and descriptive study of $\mathrm{HIV}$ infected women that have been followed up at the gynecological clinic from November 1996 to December 2002. These patients were subjected to a specific protocol which included an interview, a gynecological evaluation and a collecting cervical sample for Pap smear, research of HPV (PCR) and colposcopy. Cervical biopsy was performed when necessary. Data were stored and analyzed by Epi-Info, version 6.0.

Results: the mean age was 34.5 years. The small number of sexual partners, average of three partners, and the predominance of heterosexual contagion should be mentioned: 271 (90.6\%) patients were contaminated through sexual contact with their partners. There was a high prevalence of cervical intraepithelial neoplasia (CIN) representing $21.7 \%$ of the total group. Of 109 patients subjected to PCR, 89 (81.7\%) were found to have some HPV genotype. An inflammatory smear was present in $69 \%$ of the patients.

Conclusions: there is a high frequency of CIN and genital infectious diseases among HIV-infected women, mainly HPV.

KEYWORDS: AIDS. Human papillomavirus. Cervicovaginal smear. Uterine cervix: neoplasms. Polymerase chain reaction.

\section{Referências}

1. Thomas CQ. World AIDS day: reflections on the pandemic [online] 2003 [cited 2003 jan 24]. Available from: http:/ /www.unaids.org/worldaidsday/2002/ press / Epiupdate.html

2. Levine AM. Evaluation and management of HIVinfected women. Ann Intern Med 2002; 136:228-42.

3. Ministério da Saúde. Vigilância do HIV no Brasil: novas diretrizes. Brasília: Secretaria de Políticas de Saúde/Coordenação Nacional de DST e Aids; 2002. p.82.

4. Ministério da Saúde. Sistema Nacional de Agravos de Notificação (SINAN) [online] 2003 [Acessado em 25 jan 2003]. Disponivel em: http: / / www.aids.gov.br

5. Sobel JD. Gynecologic infections in human immunodeficiency virus-infected women. Clin Infect Dis 2000; 31:1225-33.

6. Jamieson DJ, Duerr A, Klein RS, et al. Longitudinal analysis of bacterial vaginosis: findings from the HIV epidemiology research study. Obstet Gynecol 2001; 98:656-63.

7. Zeger W, Holt K. Gynecologic infections. Emerg Med Clin North Am 2003; 21:631-48.

8. Handsfield $\mathrm{HH}$, Golden M. Epidemiologic and therapeutic data point to opportunities for improved STD control [online] 2003 [cited 2003 oct 2]. Available from: http://www.medscape.com/pages/ features/public/index.search.
9. Campos RRR. Prevalência do HPV e seus genótipos na cérvice uterina, em mulheres portadoras e não portadoras do HIV [dissertação]. Belo Horizonte: Univ. Federal de Minas Gerais; 1999.

10. Souza NST, Melo VH, Castro LPF. Diagnóstico da infecção pelo HIV em lesões do colo do útero em mulheres HIV positivas: acuidade da histopatologia. Rev Bras Ginecol Obstet 2001; 23:355-61.

11. Thomas JO. Acquired immunodeficiency syndromeassociated cancers in Sub-Saharan Africa. Semin Oncol 2001; 28:198-206.

12.Vonau B, Boag F. HIV-positive women and cervical screening. Int J STD AIDS 2000; 11:767-73.

13. Heard I, Tassie JM, Schmitz V, Mandelbrot L, Kazatchkine MD, Orth G. Increased risk of cervical disease among human immunodeficiency virusinfected women with severe immunosuppression and high human papillomavirus load. Obstet Gynecol 2000; 96:403-9.

14.Vernazza PL, Eron JJ, Fiscus SA, Cohen MS. Sexual transmission of HIV: infectiousness and prevention. AIDS 1999; 13:155-66.

15.Del Mistro A, Chieco Bianchi L. HPV-related neoplasias in HIV-infected individuals. Eur J Cancer 2001; 37:1227-35.

16.Wallace SV, Carlin EM. HIV in cervical cancer. Int $\mathrm{J}$ STD AIDS 2001; 12:283-5.

17.Zimmermmann JB. Prevalência dos genótipos do papilomavirus humano na cérvice uterina de pacientes infectadas com o virus da imunodeficiência humana e sua associação com o grau das lesões do colo uterino. Rev Bras Ginecol Obstet 2002; 24:419.

18.Auge APF, Piato $\mathrm{S}$, Frade $\mathrm{AB}$, et al. Freqüência de neoplasia intra-epitelial cervical em portadoras do vírus da imunodeficiência humana. Rev Bras Ginecol Obstet 2000; 22:573-7.

19.Jamieson DJ, Duerr A, Burk R, et al. Characterization of genital human papillomavirus infection in women who have or who are at risk of having HIV infection. Am J Obstet Gynecol 2002; 186:21-7.

20.Ferenczy A, Coutlée F, Franco E, Hankins C. Human papillomavirus and HIV coinfection and the risk of neoplasias of the lower genital tract: a review of recent developments. CMAJ 2003; 169:431-4.

21.De Palo G. Colposcopia e patologia do trato genital inferior. Rio de Janeiro: Medsi; 1996. p.491.

22.Richart RM. Historia natural de la neoplasia cervical intraepithelial. Clin Obstet Gynecol 1967; 10:14884.

23. From the Centers for Disease Control and Prevention. 1993 revised classification system for HIV infection and expanded surveillance case definition for AIDS among adolescents and adults. JAMA 1993; 269:729-30.

Recebido em: 7/3/2003 Aceito com modificações em: 14/10/03 